\title{
Radiation dose in neuroangiography using image noise reduction technology: a population study based on 614 patients
}

\author{
Michael Söderman • Maria Mauti • Sjirk Boon • \\ Artur Omar • María Marteinsdóttir • \\ Tommy Andersson • Staffan Holmin • Bart Hoornaert
}

Received: 26 June 2013 / Accepted: 15 August 2013 / Published online: 5 September 2013

(C) The Author(s) 2013. This article is published with open access at Springerlink.com

\begin{abstract}
Introduction The purpose of this study was to quantify the reduction in patient radiation dose by X-ray imaging technology using image noise reduction and system settings for neuroangiography and to assess its impact on the working habits of the physician.

Methods Radiation dose data from 190 neuroangiographies and 112 interventional neuroprocedures performed with stateof-the-art image processing and reference system settings were collected for the period January-June 2010. The system was then configured with extra image noise reduction algorithms and system settings, which enabled radiation dose reduction without loss of image quality. Radiation dose data from 174 neuroangiographies and 138 interventional neuroprocedures were collected for the period January-June 2012. Procedures were classified as diagnostic or interventional. Patient radiation exposure was quantified using cumulative dose area product and cumulative air kerma. Impact on working habits of the physician was quantified using fluoroscopy time and number of digital subtraction angiography (DSA) images.

Results The optimized system settings provided significant reduction in dose indicators versus reference system settings $(p<0.001)$ : from 124 to $47 \mathrm{~Gy} \mathrm{~cm}^{2}$ and from 0.78 to $0.27 \mathrm{~Gy}$
\end{abstract}

M. Söderman $(\bowtie) \cdot$ T. Andersson $\cdot$ S. Holmin

Department of Clinical Neuroscience, Karolinska Institute and

Department of Neuroradiology, Karolinska University Hospital -

Solna, Stockholm 17176, Sweden

e-mail:michael.soderman@karolinska.se

M. Mauti $\cdot$ S. Boon $\cdot$ B. Hoornaert

Philips Healthcare, Best, The Netherlands

A. Omar • M. Marteinsdóttir

Department of Medical Physics, Section of Imaging Physics,

Karolinska University Hospital, Stockholm, Sweden for neuroangiography, and from 328 to $109 \mathrm{~Gy} \mathrm{~cm}^{2}$ and from 2.71 to 0.89 Gy for interventional neuroradiology. Differences were not significant between the two systems with regard to fluoroscopy time or number of DSA images.

Conclusion X-ray imaging technology using an image noise reduction algorithm and system settings provided approximately $60 \%$ radiation dose reduction in neuroangiography and interventional neuroradiology, without affecting the working habits of the physician.

Keywords Angiography $\cdot$ Radiation dose $\cdot$ Radiation physics $\cdot$ Imaging technology $\cdot$ Interventional neuroradiology

\section{Introduction}

Complex neurovascular procedures may expose patients and, secondarily, staff to high doses of ionizing radiation. The potential consequences, such as erythema and hair loss, are of major concern [1]. However, in accordance with the as low as reasonably achievable (ALARA) principle, radiation doses cannot be reduced below the level necessary for acceptable clinical image quality.

An X-ray imaging technology using advanced image noise reduction algorithms combined with optimized system settings that enable dose reduction and optimal image quality was designed for digital subtraction angiography (DSA) and fluoroscopy in neuroradiology, in order to reduce patient radiation dose without impairing image quality (AlluraClarity; Philips Healthcare, Best, Netherlands). A previous study addressed non-inferiority of image quality in DSA at $75 \%$ radiation dose reduction [2]. The current study aims to quantify the radiation dose reduction in a patient cohort subjected to diagnostic neuroangiography or interventional neuroradiology and to test the hypothesis that the image noise reduction 
algorithms with optimized system settings would significantly reduce patient radiation exposure without affecting parameters such as fluoroscopy time and number of DSA images ("the working habits of the physician").

\section{Methods}

The study was approved by the local Ethical Review Board at Karolinska University Hospital, Stockholm, Sweden.

Data acquired on a system equipped with a state-of-the-art image processing with reference system settings ("reference system") was compared with data from the same system equipped with advanced image noise reduction algorithms combined with optimized system settings ("current system"). Procedure and dose data for the reference system and the current system were collected during January-June 2010 and January-June 2012, respectively. The same radiologists were employed and the same procedural techniques were used.

All examinations were performed on the same biplane flat panel detector angiography system (AlluraXper FD20/20 biplane; Philips Healthcare), equipped during the second part of the study with an image processing chain for noise reduction in DSA and fluoroscopy, combined with optimized system settings (AlluraClarity; Philips Healthcare).

The image processing chain uses several features to improve image quality. The real-time automatic pixel shift feature is used to reduce the anatomical structure noise which is introduced in the subtracted image by patient motion or accidental table motion. By minimizing this undesired noise source, quantum noise will become the dominant noise source in DSA images.

Another feature is the temporal averaging of consecutive images to create a combined mask and a combined live image.
Temporal averaging will reduce the amount of temporally uncorrelated noise such as quantum noise. Contrast detection functionality will reveal changes in the iodine bolus location and prevent this from being "diluted" by the averaging.

In the spatial noise reduction feature, the first analysis phase aims to reveal the predominant signal structures in the image, which will be excluded from the low-pass spatial filter in the second phase. The combination of phases will smooth only the parts of the image which are considered featureless.

More details about the features are described in Söderman et al. [2].

Optimization of system settings for DSA acquired with the current system included typical tube voltage $75 \mathrm{kVp}$, additional $0.1 \mathrm{~mm} \mathrm{Cu}+1 \mathrm{~mm} \mathrm{Al}$ filter, detector dose of $0.7 \mu \mathrm{Gy} / \mathrm{fr}$ on largest field of view and $0.4 \mathrm{~mm}$ focal spot size [2].

Depending on the average equivalent water thickness, the patient dose reduction for fluoroscopy, due to the lowexposure acquisition settings of the current system, can range from approximately $10 \%$ for small equivalent water thickness to approximately $50 \%$ for large equivalent water thickness, achieved, for example, with steeper projections. The average equivalent water thickness for the head is considered approximately $22 \mathrm{~cm}$ on the frontal plane and $18 \mathrm{~cm}$ for the lateral plane, over the full population range [3]. For this average water equivalent thickness, the expected patient dose reduction is $30 \%$.

Patients were subjected to neuroangiography or endovascular treatment during the study periods. Patient demographics and procedure information were collected. Patients were categorized as being subjected to diagnostic or interventional procedures. Interventional procedures were further divided in subgroups: (a) arteriovenous malformation (AVM), (b) aneurysm, (c) stroke and (d) others.

Table 1 Patient demographics

$C I$ confidence interval, $S D$ standard deviation

${ }^{a} p$-Value (two-sided) from ANOVA for continuous parameters, and from Chi-squared test for categorical parameters

${ }^{b}$ The number of interventions was 112 for the reference system, 138 for the current system, and 250 in total

\begin{tabular}{lllll}
\hline Characteristic & $\begin{array}{l}\text { Reference system } \\
(n=302)\end{array}$ & $\begin{array}{l}\text { Current system } \\
(n=312)\end{array}$ & $\begin{array}{l}\text { Total } \\
(N=614)\end{array}$ & $p$-Value $^{\mathrm{a}}$ \\
\hline Age (years) & & & & $<0.001$ \\
Mean \pm SD & $51.6 \pm 17.6$ & $56.5 \pm 17.4$ & $54.1 \pm 17.7$ & \\
$95 \%$ CI & $49.6-53.6$ & $54.6-58.4$ & $52.7-55.5$ & \\
Median & 53.0 & 59.0 & 56.0 & \\
Min-Max & $0-91$ & $1-91$ & $0-91$ & 0.212 \\
Procedure duration (min) & & & & \\
Mean \pm SD & $58.5 \pm 54.0$ & $64.2 \pm 58.9$ & $61.4 \pm 56.6$ & \\
95\% CI & $52.4-64.6$ & $57.6-70.8$ & $56.9-65.9$ & \\
Median & 35.0 & 40.0 & 39.5 & \\
Min-Max & $5-260$ & $5-325$ & $5-325$ & \\
Intervention procedures, ${ }^{\mathrm{b}} n(\%)$ & & & $13(5.2)$ & \\
AVM & $9(8.0)$ & $4(2.9)$ & $64(25.6)$ & \\
Aneurysm & $26(23.2)$ & $38(27.5)$ & $86(34.4)$ & \\
Stroke & $41(36.6)$ & $45(32.6)$ & $87(34.8)$ & \\
Other & $36(32.1)$ & $51(37.0)$ & \\
\hline
\end{tabular}


Fig. 1 Distribution of DAP values for diagnostic procedures. Dashed lines represent third quartile (Q3). For graph layout purposes, the $x$-axis is limited to

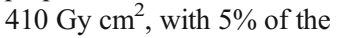
procedures for the reference system not being displayed on the scale (max value is $2,997 \mathrm{~Gy} \mathrm{~cm}^{2}$ )
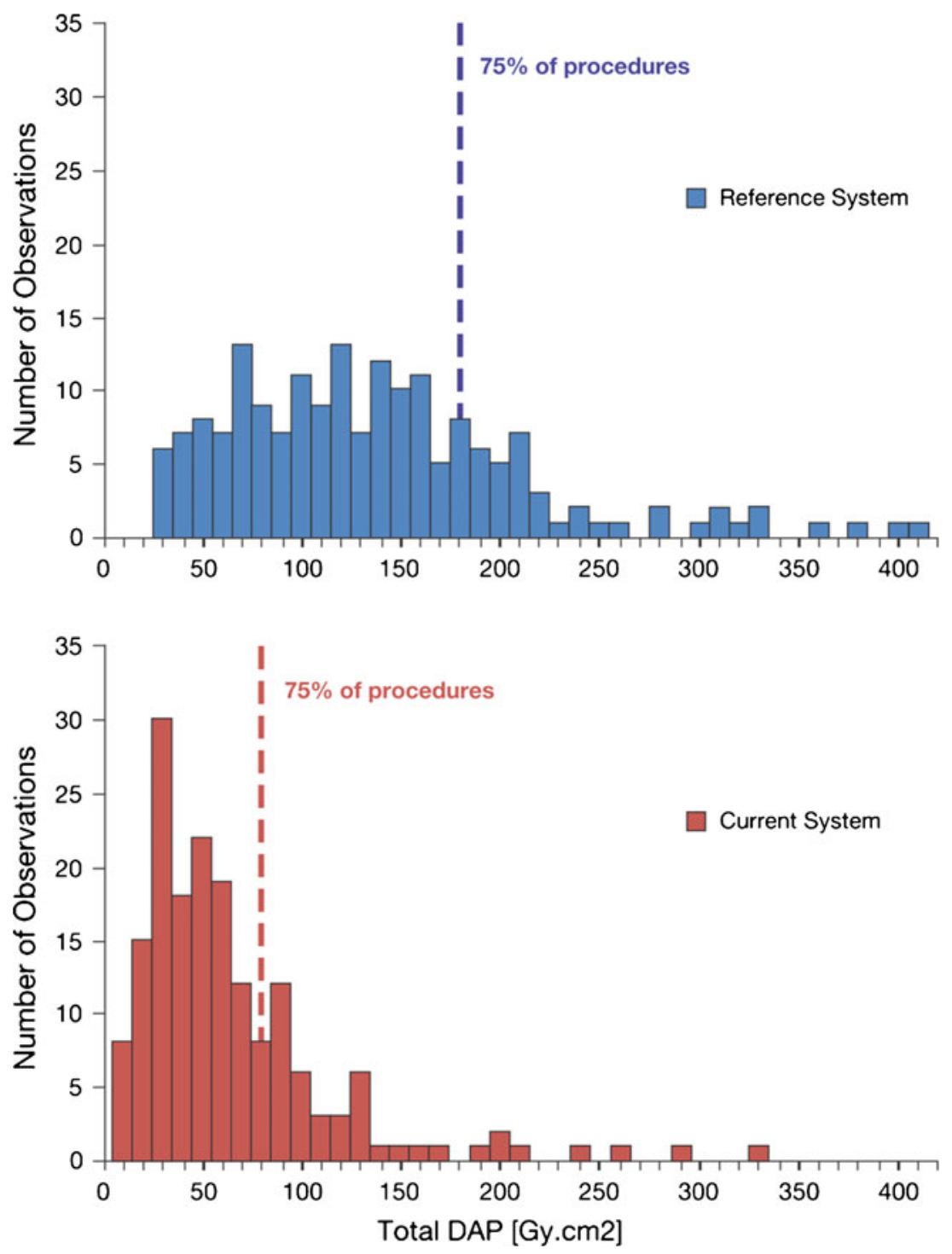

Patient radiation dose indicators, quantified as (cumulative) dose area product (DAP) and cumulative air kerma (CAK), as well as acquisition parameters, such as number of DSA images, fluoroscopy time, procedure time, and number of DSA runs, were collected.

The equipment displayed the updated cumulative dose-area product (DAP), measured by the internal transmission ionization chambers (KermaX plus; IBA Dosimetry, Schwarzenbruck, Germany) configured in both planes.

The inherent dose-report system in the angiography equipment provided information, measured in Gy $\mathrm{cm}^{2}$, of DAP fluoroscopy, DAP exposure, and total DAP (sum of DAP fluoroscopy and DAP exposure). DAP exposure indicated the DAP for all DSA acquisitions stored in the system. CAK at the patient entrance reference point for frontal and lateral channels was provided in Gy. This information was sent via modality performance procedure step (MPPS) automatically to the radiology information system (RIS; Carestream, Vaughan, Canada)

The primary outcome of the study was radiation dose quantified as DAP and CAK. Secondary outcomes were fluoroscopy time, number of DSA images, number of DSA runs, and procedure duration.

\section{Statistical analysis}

Descriptive statistics were used to describe patient and procedure characteristics, with differences between reference and current system evaluated with one-way analysis of variance (ANOVA) models at a significance level of $\alpha=0.05$. Differences in exposure between the reference and the current systems were compared using ANOVA with least square mean dose values, using an $\underline{F}$-test. Secondary covariance analyses were performed for DAP, CAK, and acquisition measures 
Fig. 2 Distribution of DAP values for interventional procedures. Dashed lines represent third quartile. For graph layout purposes, the $x$-axis is limited to $900 \mathrm{~Gy} \mathrm{~cm}^{2}$, with $5 \%$ of the procedures for the reference system not being displayed on the scale (max value is $1,114 \mathrm{~Gy} \mathrm{~cm}^{2}$ )
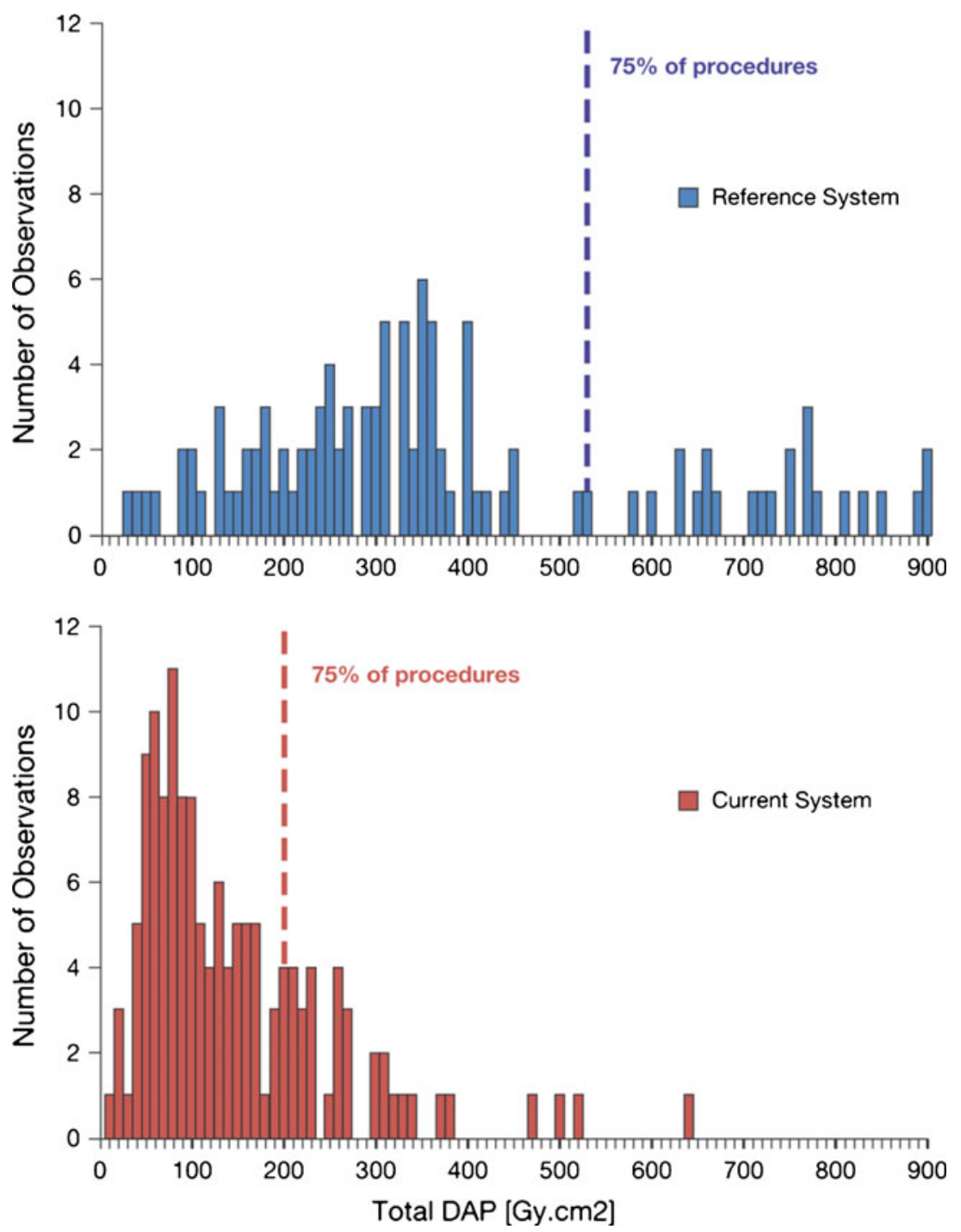

(analysis of covariance) to determine potential impact of demographic differences or type of intervention.

\section{Results}

\section{Subjects}

A total of 620 patients were included in the data collection; however, 4 patients were excluded because the radiation dose data information was incomplete, and 2 patients were excluded because they were classified as diagnostic and treatment together. Therefore, 614 patients were analyzed. Patient baseline characteristics are summarized in Table 1 . The reference system group included 302 patients (172 females and 130 males) divided in 190 diagnostic and 112 interventional procedures. The current system group included 312 patients (172 females and 140 males) divided in 174 diagnostic and 138 interventional procedures. For both groups, the number of AVMs is very small; therefore, procedural dose reduction will not be calculated. The mean age for both groups was $54.1 \pm 17.7$ years; however, patients treated with the current system were older than those treated with the reference system $(p<0.001)$.

\section{Cumulative DAP}

DAP values were highly skewed with large variability (Figs. 1 and 2). Patient exposure and number of images were higher for interventional procedures compared with diagnostic procedures. For diagnostic procedures, median total DAP and median DAP exposure with the current system decreased from 124 to $47 \mathrm{~Gy} \mathrm{~cm}^{2}$ and from 113 to $36 \mathrm{~Gy} \mathrm{~cm}^{2}$, respectively (Table 2). Both reductions were significant $(p<0.001)$. Based on geometric means, the patient radiation dose reduction was $62 \%$ for total DAP and $69 \%$ for DAP exposure. 
Table 2 Descriptive summary of DAP values for diagnostic and interventional procedures
$C I$ confidence interval, $S D$ standard deviation, $Q 1$ first quartile, Q3 third quartile

\begin{tabular}{|c|c|c|c|c|}
\hline \multirow[t]{2}{*}{ Variable } & \multicolumn{2}{|l|}{ Diagnostic } & \multicolumn{2}{|l|}{ Intervention } \\
\hline & $\begin{array}{l}\text { Reference system } \\
(n=190)\end{array}$ & $\begin{array}{l}\text { Current system } \\
(n=174)\end{array}$ & $\begin{array}{l}\text { Reference system } \\
(n=112)\end{array}$ & $\begin{array}{l}\text { Current system } \\
(n=138)\end{array}$ \\
\hline \multicolumn{5}{|c|}{ DAP fluoroscopy, $\left(\mathrm{Gy} \mathrm{cm}^{2}\right)$} \\
\hline Mean \pm SD & $17.2 \pm 45.7$ & $14.6 \pm 20.8$ & $85.4 \pm 68.5$ & $55.5 \pm 47.3$ \\
\hline Median & 9 & 8 & 70 & 42 \\
\hline Q1-Q3 & $6-17$ & $5-15$ & $33-119$ & $21-75$ \\
\hline Min-Max & $1-593$ & $1-179$ & $1-291$ & $1-245$ \\
\hline $95 \%$ CI & $10.7-23.8$ & $11.5-17.7$ & $72.6-98.3$ & $47.5-63.4$ \\
\hline \multicolumn{5}{|c|}{ DAP exposure $\left(\mathrm{Gy} \mathrm{cm}^{2}\right)$} \\
\hline Mean \pm SD & $145.2 \pm 190.0$ & $46.1 \pm 39.8$ & $304.5 \pm 199.3$ & $86.2 \pm 71.0$ \\
\hline Median & 113 & 36 & 253 & 66 \\
\hline Q1-Q3 & $72-161$ & $22-56$ & $172-386$ & $39-118$ \\
\hline Min-Max & $18-2,404$ & $1-247$ & $19-952$ & $7-455$ \\
\hline $95 \% \mathrm{CI}$ & $118.0-172.4$ & $40.2-52.1$ & $267.2-341.8$ & $74.2-98.1$ \\
\hline \multicolumn{5}{|c|}{ Total DAP $\left(\mathrm{Gy} \mathrm{cm}^{2}\right)$} \\
\hline Mean \pm SD & $162.2 \pm 231.7$ & $60.4 \pm 51.1$ & $389.9 \pm 247.0$ & $141.7 \pm 106.6$ \\
\hline Median & 124 & 47 & 328 & 109 \\
\hline Q1-Q3 & $78-179$ & $28-76$ & $225-518$ & $67-196$ \\
\hline Min-Max & $21-2,997$ & $7-325$ & $28-1,114$ & $8-635$ \\
\hline $95 \%$ CI & $129.0-195.4$ & $52.8-68.1$ & $343.7-436.2$ & $123.7-159.6$ \\
\hline
\end{tabular}

For interventional procedures, there was a dose reduction from 328 to $109 \mathrm{~Gy} \mathrm{~cm}^{2}$ for total DAP, from 70 to $42 \mathrm{~Gy} \mathrm{~cm}^{2}$ for DAP fluoroscopy, and from 253 to $66 \mathrm{~Gy} \mathrm{~cm}^{2}$ for DAP exposure, based on median values (Table 2); the differences were significant $(p<0.001)$. Based on geometric means, the

Table 3 Descriptive summary of CAK values for diagnostic and interventional procedures

\begin{tabular}{lllll}
\hline Variable & \multicolumn{1}{c}{ Diagnostic } & \multicolumn{3}{c}{ Intervention } \\
& $\begin{array}{c}\text { Reference } \\
\text { system }\end{array}$ & $\begin{array}{c}\text { Current } \\
\text { system }\end{array}$ & $\begin{array}{c}\text { Reference } \\
\text { system }\end{array}$ & $\begin{array}{c}\text { Current } \\
\text { system }\end{array}$ \\
\hline $\begin{array}{l}\text { CAK frontal } \\
\text { channel, Gy }\end{array}$ & $n=190$ & $n=174$ & $n=111$ & $n=138$ \\
Mean \pm SD & $0.78 \pm 0.89$ & $0.31 \pm 0.33$ & $2.56 \pm 1.74$ & $0.97 \pm 0.89$ \\
Median & 0.59 & 0.21 & 2.06 & 0.68 \\
Q1-Q3 & $0.35-0.91$ & $0.13-0.37$ & $1.22-3.65$ & $0.38-1.35$ \\
Min-Max & $0.08-10.48$ & $0.03-2.21$ & $0.27-7.34$ & $0.04-5.15$ \\
95\% CI & $0.65-0.91$ & $0.26-0.36$ & $2.23-2.89$ & $0.82-1.12$ \\
CAK lateral & $n=188$ & $n=170$ & $n=111$ & $n=135$ \\
$\quad$ channel, Gy & $0.26 \pm 0.28$ & $0.10 \pm 0.16$ & $0.94 \pm 0.86$ & $0.38 \pm 0.51$ \\
Mean \pm SD & 0.19 & 0.06 & 0.65 & 0.21 \\
Median & $0.11-0.31$ & $0.03-0.11$ & $0.32-1.25$ & $0.10-0.45$ \\
Q1-Q3 & $0.02-2.88$ & $0.00-1.49$ & $0.06-4.86$ & $0.01-3.18$ \\
Min-Max & $0.22-0.30$ & $0.07-0.12$ & $0.78-1.10$ & $0.29-0.47$ \\
95\% CI & & & &
\end{tabular}

$C I$ confidence interval, $S D$ standard deviation, $Q 1$ first quartile, $Q 3$ third quartile patient radiation dose reduction was $65 \%, 33 \%$, and $73 \%$ for total DAP, DAP fluoroscopy, and DAP exposure, respectively. For both diagnostic and interventional procedures, the first quartile (Q1) DAP for the reference system exceeded the third quartile $(\mathrm{Q} 3)$ of the DAP for the current system, except for DAP fluoroscopy.

Regardless of the interventional subgroup, DAP values decreased. The dose reduction (total DAP) was approximately $70 \%, 60 \%$, and $65 \%$ for aneurysm, stroke, and other categories, respectively, based on geometric means.

Secondary analyses were performed to evaluate the impact of age on DAP values because patient age was statistically significantly different between the reference system and current system group, for interventional procedures. There was no effect of age on DAP in the interventional procedure group $(p=0.2597)$.

\section{Cumulative air kerma}

CAK values were highly skewed with large variability. For diagnostic angiographies the median CAK values were reduced from 0.78 to 0.27 Gy for frontal and lateral channel together, with reduction from 0.59 to $0.21 \mathrm{~Gy}$ and from 0.19 to 0.06 Gy for the frontal and lateral channels, respectively (Table 3); the difference was significant $(p<0.001)$. The dose reduction for the diagnostic procedures was $62 \%$ on the frontal channel and $67 \%$ on the lateral channel based on geometric 
Table 4 Descriptive summary of acquisition settings for diagnostic and interventional procedures
$C I$ confidence interval, $S D$ standard deviation, $Q 1$ first quartiler, Q3 third quartile

\begin{tabular}{|c|c|c|c|c|}
\hline \multirow[t]{2}{*}{ Variable } & \multicolumn{2}{|l|}{ Diagnostic } & \multicolumn{2}{|l|}{ Intervention } \\
\hline & $\begin{array}{l}\text { Reference system } \\
(n=190)\end{array}$ & $\begin{array}{l}\text { Current system } \\
(n=174)\end{array}$ & $\begin{array}{l}\text { Reference system } \\
(n=112)\end{array}$ & $\begin{array}{l}\text { Current system } \\
(n=138)\end{array}$ \\
\hline \multicolumn{5}{|c|}{ No. of acquired exposures/DSA images } \\
\hline Mean \pm SD & $291.7 \pm 181.3$ & $310.6 \pm 192.5$ & $625.8 \pm 445.2$ & $635.7 \pm 506.1$ \\
\hline Median & 266 & 278 & 525 & 464 \\
\hline Q1-Q3 & $160-385$ & $173-402$ & $292-870$ & $299-845$ \\
\hline Min-Max & $30-1,096$ & $1-1,434$ & $50-2,327$ & $108-2,986$ \\
\hline $95 \% \mathrm{CI}$ & $265.8-317.6$ & $281.7-339.4$ & $542.5-709.2$ & $550.5-720.9$ \\
\hline \multicolumn{5}{|c|}{ Fluoroscopy time (min) } \\
\hline Mean \pm SD & $7.1 \pm 4.2$ & $7.2 \pm 4.5$ & $12.5 \pm 6.4$ & $11.0 \pm 6.6$ \\
\hline Median & 6 & 6 & 13 & 12 \\
\hline Q1-Q3 & $4-9$ & $4-9$ & $7-17$ & $5-16$ \\
\hline Min-Max & $0-22$ & $0-22$ & $1-24$ & $0-23$ \\
\hline $95 \% \mathrm{CI}$ & $6.5-7.7$ & $6.6-7.9$ & $11.3-13.7$ & $9.9-12.1$ \\
\hline
\end{tabular}

means. The median CAK values for interventional procedures diminished from 2.71 to 0.89 Gy for frontal and lateral channel together, with reduction from 2.06 to 0.68 Gy and from 0.65 to 0.21 Gy for frontal and lateral channels, respectively. The difference was significant $(p<0.001)$. The dose reduction was $66 \%$ on the frontal channel and $67 \%$ on the lateral channel based on geometric means.

Regardless of the interventional subgroup, CAK values were reduced for both frontal and lateral channels. Age had no impact on CAK for patients subjected to interventional procedures. In general, intervention type did not affect CAK analyses.

\section{Acquisition parameters}

Acquisition parameter data showed a large variability. Fluoroscopy time and number of exposure images obtained were substantially higher for interventional procedures (Table 4). The difference in fluoroscopy time, number of DSA images, number of DSA runs, and procedure duration did not reach statistical significance.

\section{Discussion}

The aim of the study was to quantify the impact of X-ray imaging technology using image noise reduction image processing combined with optimized system settings on patient radiation dose indicators and to assess its effects on the working habits of the physician.

This study confirmed dose reduction for DAP exposure to be $69 \%$ and $73 \%$ for diagnostic and interventional procedures, respectively, based on geometric means. Similar results were obtained in previously published work where comparison was based on two DSA acquisitions, performed with reference and current system settings, on the same patient [2]. Patient dose reduction in fluoroscopy was 33\% for interventional neuroradiology based on geometric means. For diagnostic and interventional procedures together, patient radiation dose reduction for total DAP (sum of DAP fluoroscopy and DAP exposure) and CAK was approximately $60 \%$. Fluoroscopy time and number of DSA images were both unaffected.

Similar to published analyses of patient exposure in interventional neuroradiology [3-7], this study reported wide variability in radiation exposure and acquisition parameters, with variation per procedure type [8] and diagnostic versus interventional procedure $[3,9,10]$. Comparison with other studies is troublesome because metrics used are often different. Some authors report peak skin dose, measured or estimated [11, 12], whereas we report DAP and CAK as displayed by the angiography system.

The RAD-IR study [4] reports mean DAP values of 320 Gy $\mathrm{cm}^{2}$ for 382 cases including embolization of aneurysm and AVM. Vano et al. [7] reports a mean DAP value of 305 Gy $\mathrm{cm}^{2}$ and a median DAP value of $256 \mathrm{~Gy} \mathrm{~cm}^{2}$ for $172 \mathrm{embo-}$ lization procedures. However, D'Ercole et al. [5] reports a higher median value of $352 \mathrm{~Gy} \mathrm{~cm}^{2}$ for 82 procedures. The RAD-IR study [4] also reported CAK values of 3.8 Gy for interventional neuroradiology procedures among patients with AVM and aneurysm. The study by Vano et al. [7] reported a CAK median of 2.4 Gy and a CAK third quartile (Q3) value of 3.9 Gy for cerebral embolizations. These data are in agreement with our results obtained with reference dose settings.

The 2009 Society of Interventional Radiology guidelines [13] recommend operators to be notified anytime CAK values exceed 3 Gy and then every 1 Gy thereafter, or anytime DAP 
exceeds $300 \mathrm{~Gy}^{2} \mathrm{~cm}^{2}$, and subsequently at increments of $100 \mathrm{~Gy} \mathrm{~cm}^{2}$. Less than $4 \%$ of diagnostic procedures performed with reference system exceeded the threshold values for CAK (sum of frontal and lateral channels) and about 9\% exceeded the threshold for DAP. Only in $1 \%$ of the cases undergoing diagnostic procedures performed with the current system exceeded the threshold for CAK, and $<1 \%$ exceeded the threshold for DAP. However, about $47 \%$ of interventional procedures performed with the reference system exceeded CAK values, and $58 \%$ exceeded DAP threshold values. The RAD-IR study reported $55 \%$ and $67 \%$ of AVM and aneurysm procedures to be greater than 3 Gy [4]. The percentage of interventional procedures performed with the current system that exceeded the threshold values was reduced; CAK threshold is exceeded in $10 \%$ of cases, whereas DAP in $8 \%$ of cases.

In this study, DSA provides about $70-80 \%$ of the total procedure dose. Other studies report similar values [2, 14] including the baseline study that this study is based on. With the patient radiation dose reduction in DSA seen with the current system, the relation fluoroscopy-DSA changes making the contribution of fluoroscopy equally relevant on total procedure radiation load (fluoroscopy contributes for about $40 \%$ and DSA for about $60 \%$ ).

\section{Limitations to the study}

Interpreting data from this study is limited by those factors inherent to retrospective design including the inability to match patients. In addition, the clinical complexity of the procedure and comparative image quality has not been taken into account in the study. Although data were obtained at the same facility with the same clinical staff for the two recording periods, it was not possible to determine if other patient dose reduction measures, such as further collimation, were implemented in the current system group. However, the reduction in DAP exposure observed in this study is in the same range as that observed in a previously published work, where comparison was based on the same patient for DSA acquisition [2]. Thus the patient dose reduction is likely the effect of the optimized system settings.

\section{Conclusion}

The image noise reduction X-ray imaging technology in combination with optimized system settings, which enable dose reduction and optimal image quality, reduced patient radiation doses in DSA and fluoroscopy by approximately $60 \%$; there was no impact on physician working habits.

Acknowledgment We gratefully acknowledge Ms. Charlotta (Lotta) Palmgren at the Hospital Physics Department of the Karolinska University Hospital for fruitful discussions.
Conflict of interest M. Söderman received money from Philips Healthcare for research collaboration. M. Mauti, S. Boon, and B. Hoornaert are employees of Philips Healthcare.

Open Access This article is distributed under the terms of the Creative Commons Attribution License which permits any use, distribution, and reproduction in any medium, provided the original author(s) and the source are credited.

\section{References}

1. Stewart FA, Akleyev AV, Hauer-Jensen M, Hendry JH, Kleiman NJ, MacVittie TJ, Aleman BM, Edgar AB, Mabuchi K, Muirhead CR, Shore RE, Wallace WH (2012) ICRP Publication 118: ICRP statement on tissue reactions and early and late effects of radiation in normal tissues and organs - threshold doses for tissue reactions in a radiation protection context. Ann ICRP 41(1-2):1-322

2. Söderman M, Holmin S, Andersson T, Palmgren C, Babić D, Hoornaert B (2013) Clinical results with an image noise reduction algorithm for digital subtraction angiography. Radiology. doi:10. 1148/radiol.13121262

3. Gkanatsios NA, Huda W, Peters KR (2012) Adult patient doses in interventional neuroradiology. Med Phys 29:717-723

4. Miller DL, Balter S, Cole PE, Lu HT, Schueler BA, Geisinger M, Berenstein A, Albert R, Georgia JD, Noonan PT, Cardella JF, St George J, Russell EJ, Malisch TW, Vogelzang RL, Miller GL 3rd, Anderson J (2003) Radiation doses in interventional radiology procedures: the RAD-IR study: Part I. Overall measures of dose. J Vasc Interv Radiol 14:711-727

5. D'Ercole L, Thyrion FZ, Bocchiola M, Mantovani L, Klersy C (2012) Proposed local diagnostic reference levels in angiography and interventional neuroradiology and a preliminary analysis according to the complexity of the procedures. Phys Med 28:61-70

6. O'Dea TJ, Geise RA, Ritenour ER (1999) The potential for radiationinduced skin damage in interventional neuroradiological procedures: a review of 522 cases using automated dosimetry. Med Phys 26: 2027-2033

7. Vano E, Fernandez JM, Sanchez RM, Martinez D, Ibor LL, Gil A, Serna-Candel C (2013) Patient radiation dose management in the follow-up of potential skin injuries in neuroradiology. AJNR Am J Neuroradiol 34:277-282

8. Alexander MD, Oliff MC, Olorunsola OG, Brus-Ramer M, Nickoloff EL, Meyers PM (2010) Patient radiation exposure during diagnostic and therapeutic interventional neuroradiology procedures. J Neurointerv Surg 2:6-10

9. Bor D, Çekirge S, Türkay T, Turan O, Gülay M, Onal E, Cil B (2005) Patient and staff doses in interventional neuroradiology. Radiat Prot Dosimetry 117:62-68

10. Sarycheva S, Golikov V, Kalnicky S (2010) Studies of patient doses in interventional radiological examinations. Radiat Prot Dosimetry 139:258-261

11. Suzuki S, Furui S, Matsumaru Y, Nobuyuki S, Ebara M, Abe T, Itoh D (2008) Patient skin dose during neuroembolization by multiplepoint measurement using a radiosensitive indicator. AJNR Am J Neuroradiol 29:1076-1081

12. D'Ercole L, Mantovani L, Thyrion FZ, Bocchiola M, Azzaretti A, Di Maria F, Saluzzo CM, Quaretti P, Rodolico G, Scagnelli P, Andreucci L (2007) A study on maximum skin dose in cerebral embolization procedures. Am J Neuroradiol 28:503-507

13. Stecker MS, Balter S, Towbin RB, Miller DL, Vañó E, Bartal G, Angle JF, Chao CP, Cohen AM, Dixon RG, Gross K, Hartnell GG, Schueler B, Statler JD, de Baère T, Cardella JF, SIR Safety and 
Health Committee; CIRSE Standards of Practice Committee (2009) Guidelines for patient radiation dose management. J Vasc Interv Radiol 20(7 Suppl):S263-S273
14. Pitton MB, Kloeckner R, Schneider J, Ruckes C, Bersch A, Düber C (2012) Radiation exposure in vascular angiographic procedures. J Vasc Interv Radiol 23:1487-1495 